\title{
Prevalence of Plasmodium falciparum Among New Intakes in the Isaac Jasper Boro College of Education, Sagbama, Bayelsa State, Nigeria
}

\author{
Amawulu Ebenezer ${ }^{1, *}$, Peace Eekpa ${ }^{2}$ \\ ${ }^{1}$ Department of Biological Sciences, Niger Delta University, Wilberforce Island, Amassoma, Nigeria \\ ${ }^{2}$ Department of Biology, Isaac Jasper Boro College of Education, Sagbama, Nigeria \\ Email address: \\ ebenezeramawulu@gmail.com (A. Ebenezer) \\ ${ }^{*}$ Corresponding author \\ To cite this article: \\ Amawulu Ebenezer, Peace Eekpa. Prevalence of Plasmodium falciparum Among New Intakes in the Isaac Jasper Boro College of Education, \\ Sagbama, Bayelsa State, Nigeria. American Journal of Biomedical and Life Sciences. Vol. 6, No. 2, 2018, pp. 33-36. \\ doi: 10.11648/j.ajbls.20180602.11 \\ Received: April 21, 2018; Accepted: May 14, 2018; Published: May 31, 2018

\begin{abstract}
This study investigated the prevalence of Plasmodium falciparum among new intake of the Isaac Jasper Boro College of Education, Sagbama during January-March, 2017. Blood samples were collected through venal puncture. A $2.5 \mathrm{ml}$ part of blood was collected from each student and transferred into an anti- coagulant bottle. Malaria parasites were determined using Pf malaria rapid test kitsanda standard microscopy. The preparation of the test kits and microscopy followed standard procedures. Determination of positive slides followed standard techniques. Data were analyzed using descriptive and inferential statistics. Malaria was positive slides were $15.49 \%$ of the total slides. Plasmodium falciparum accounted for $100 \%$ of all the positive cases. Male $(18.75 \%)$ were more infected than female $(12.82 \%)$. The difference was significant $\left(\chi^{2}\right.$ cal $=$ $16.68, \mathrm{p}<0.05)$. The prevalence of $P$. falciparum varies with the age across age group. The age bracket29-31(25.0\%) had more prevalence, followed by age bracket 17-19 (17.65\%). Least prevalence $(9.09 \%)$ was recorded among age bracket 23-25. Differences were not significant $\left(\chi^{2} \mathrm{cal}=7.96, \mathrm{p}>0.05\right)$. Prevalence of $P$. falciparum varied across departments. The differences were statistically significant $\left(\chi^{2} \mathrm{cal}=57.71, \mathrm{p}>0.05\right)$. The result is a public health concern and call for prompt intervention.
\end{abstract}

Keywords: Plasmodium falciparum, Rapid Test Kit, Students, Bayelsa State

\section{Introduction}

Malaria, more than any other diseases in tropical Africa is responsible for $>300-500$ million cases and 1.5-2.7 deaths recorded annually worldwide [1]. Malaria is caused by a protozoan parasite of the genus Plasmodium. Four species had been responsible for its transmission in humans. They are P. falciparum, P. Vivax, P. Ovale, P. malariae.

Plasmodium infection remains an important cause of mortality and morbidity in many parts of the world and causes adverse effect on the population both on the health and socio-economic activities [2]. In Nigeria alone, malaria accounts for $25 \%$ of under-five mortality, $30 \%$ of childhood mortality and $11 \%$ of maternal mortality [3]. P. falciparum induced malaria is a life threatening disease [2]. In Nigeria, a large proportion of the populace harbour parasites without presenting clinical signs. These sets of people are considered asymptomatic patient. Asymptomatic carriers do not usually seek treatment for their infection and therefore constitute a reservoir of parasites where many people congregate [4].

School environments are likely good arena where malaria parasites can easily be transmitted [5-6]. Students constitute varied population of asymptomatic carriers and symptomatic patients. Studies have shown that the disease canimpact negatively on performance and learning outcome of school children [7]. Among the school students, malaria was responsible for greater percentages of outpatient visit [8], $28 \%$ of school absenteeism [9], poor academic performance, examination failure and school dropouts [10]. It had also been reported that Nigerian school children miss an estimated 3-12 schooldays per year, which is $2-6 \%$ of school year [11].

Despite several studies on malaria among tertiary 
institution in Nigeria $[6,12-15]$, there is no available report from the tertiary institutions in Bayelsa State. A quick diagnosis is a basic pre-requisite for reducing the morbidity and mortality of malaria infection among students. The study on the prevalence of Plasmodium falciparum among new intake in Isaac Jasper Boro College of Education, Bayelsa State is a pioneering study. The outcome of this study shall guide the management on the need to protect students living in the hostel from further malaria transmission.

\section{Materials and Method}

\subsection{Study Area}

This study was conducted in Isaac Jasper Boro College of Education (IJBCOE), Sagbama. Sagbama is the Headquarter of Sagbama Local Government Area of Bayelsa State. It is bounded by the longitude $6^{0} 14^{\mathrm{E}}$ and latitude $5^{0} 9^{\mathrm{N}}$.

\subsection{Study Design}

The study adopted a descriptive survey design to determine the prevalence of Plasmodium falciparum among new student from January -March, 2017.

\subsection{Sample and Sampling Technique}

The samples were all new intakes students presented for the institutional routine medical examination. The sample size consisted of seven hundred and ten (710) students; 320 males and 390 female.

\subsection{Ethical Consideration}

Verbal consideration was obtained from the institutional heads and the medical director of the institution's sick bay. Consents of the students through the Dean of student affairs were also obtained after when the purpose of the study was expanded.

\subsection{Method of Data Collection and Sample Preparation}

Blood samples were collected from the students using veni puncture according to standard procedures [16-17]. $2.5 \mathrm{ml}$ parts of the blood were collected using syringes and transferred into anti-coagulant bottles.

Both Pf malaria rapid test kit and routine microscopy was adopted to assess malaria positive slide. To assess Malaria parasites using Rapid test kit, one drop of the blood sample was introduced into the well in the kit; followed by 1-2 drops of buffer. The kits were allowed to rest in a plane surface for 15 minutes. Readings were taken after 15 minutes. A malaria positive sample showed two bands, one on control and other on test spot. A negative sample showed only one band. Both malaria positive and negative slides were confirmed by an experienced microscopist. Conformation of positive malaria slides followed standard procedures [17]

\subsection{Method of Data Analysis}

Data obtained were organised and analysed using descriptive statistics. Simple percentage was used to represent the frequency of all positive $P$. falciparum. Relationship between $P$. falciparum and sexes and ages were analysed using chi-square.

\section{Results}

\subsection{Demographic Information}

A total of seven hundred and ten students were involved in the study. Male represented $45.07 \%$ while $54.93 \%$ of the total students were the female (table 1). The age classification of the students are 17-19yrs, 20-22yrs, 23-25yrs, 26-28yrs, 29$31 \mathrm{yrs}, 32-34 \mathrm{yrs}, 35-37 \mathrm{yrs}, 38$ and above. The highest $(22.5 \%)$ students were in the age bracket 20-22. The details about the demographic information of student vary across department. The highest student enrolment for the study was recorded in the department of social studies with a prevalence of $28.17 \%$, followed by integrated science department (22.54\%). The least department enrolment was primary education studies, physical/health education, mathematics and Christian religious studies with a prevalence of $1.41 \%$. Department are shown in table 1 .

Table 1. Demographic Information.

\begin{tabular}{lll}
\hline VARIABLES & NO. COUNTED & \% COUNTED \\
\hline Sex & & \\
Male & 320 & 45.07 \\
Female & 390 & 54.93 \\
Age & & \\
$17-19$ & 170 & 23.94 \\
$20-22$ & 310 & 43.66 \\
$23-25$ & 110 & 15.49 \\
$26-28$ & 60 & 8.45 \\
$29-31$ & 40 & 5.63 \\
$32-34$ & 20 & 2.82 \\
$35-37$ & 0 & 0.00 \\
38 and above & 0 & 0.00 \\
Department & & \\
ISC & 160 & 22.54 \\
PES & 10 & 1.41 \\
BED & 150 & 21.13 \\
CSC & 50 & 7.04 \\
PHE & 10 & 1.41 \\
SOS & 200 & 28.17 \\
HIS & 10 & 1.41 \\
AED. & 50 & 7.04 \\
MTH & 10 & 1.41 \\
CRS & 10 & 1.41 \\
ENG & 50 & 7.04 \\
\hline
\end{tabular}

ISC $=$ Integrated Science, PES=Primary Education Study, BED=Business Education, $\mathrm{CSC}=\mathrm{Computer}$ study, $\mathrm{PHE}=$ Physical and Health Education, SOS=Social Study, HIS=History, $\mathrm{AED}=$ Agric. Education, $\mathrm{MTH}=$ Mathematics, $\mathrm{CRS}=$ Christian Religious Study, ENG=English

\subsection{Prevalence of P. falciparum Among New Intake Students During January-March, 2017}

Out of 710 students examined, $110(15.49 \%)$ were positive for malaria parasite. Plasmodium falciparum was $100 \%$ of all the positive cases. Sixty $(18.75 \%)$ of the positive cases were male while fifty $(12.82 \%)$ were female. The difference was 
significant $\left(\chi^{2}\right.$ cal $=16.68, \chi^{2}$ table $\left.=3.841, \mathrm{df}=1, \mathrm{p}<0.05\right)$ table 2 . The prevalence of $P$. falciparum varies with the age bracket. More prevalence $(25.0 \%)$ was recorded among age bracket 29-31. This is followed by age bracket 17-19 (17.65\%). Age bracket 26-28 (16.6\%), 20-22 (16.13) while the least prevalence $(9.09 \%)$ was recorded among age bracket 23-25. Differences were not significant $\left(\chi^{2} \mathrm{cal}=7.96\right.$, $\left.\chi^{2} \mathrm{tab}=14.067, \mathrm{df}=7, \mathrm{p}>0.05\right)$ table 3. P. falciparum was prevalence in four (4) departments. P. falciparum was highest $(26.67 \%)$ in the department of Business Education, followed by other ISC (25.0\%), Agric Education (20.0\%), SOS $(10.0 \%)$ respectively. The differences were statistically significant $\left(\chi^{2}\right.$ cal $=57.71, \chi^{2}$ table $\left.=18.307, \mathrm{df}=10, \mathrm{p}>0.05\right)$ table 3 .

Table 2. Prevalence of P. falciparum by sex.

\begin{tabular}{llllll}
\hline Sex & No. counted & No. positive & \%positive & $\chi^{2}$ cal & df \\
\hline Male & 320 & 60 & 18.75 & 16.68 & 1 \\
Female & 390 & 50 & 12.82 & & \\
Total & 710 & 110 & 15.49 & & \\
\hline
\end{tabular}

Table 3. Prevalence of P. falciparum by age.

\begin{tabular}{llllll}
\hline Age & No. counted & No. positive & \%positive & df & P=0.05 \\
\hline $17-19$ & 170 & 30 & 17.65 & & \\
$20-22$ & 310 & 50 & 16.13 & 7.96 & 7 \\
$23-25$ & 110 & 10 & 9.09 & 0.500 \\
$26-28$ & 60 & 10 & 16.67 & \\
$29-31$ & 40 & 0 & 0.00 & \\
$32-34$ & 20 & 0 & 0.00 & \\
$35-37$ & 0 & 0 & 0 & \\
38 & 0 & & & \\
\hline
\end{tabular}

Table 4. Prevalence of P. falciparumby Department.

\begin{tabular}{|c|c|c|c|c|c|c|}
\hline Dept & No. counted & No. positive & \%positive & $\chi^{2}$ cal & df & $\mathrm{P}=0.05$ \\
\hline ISC & 160 & 40 & 25.00 & \multirow{10}{*}{57.71} & \multirow{10}{*}{10} & \multirow{10}{*}{0.32} \\
\hline PES & 10 & 0 & 0.00 & & & \\
\hline BED & 150 & 40 & 26.00 & & & \\
\hline CSC & 50 & 0 & 0.00 & & & \\
\hline PHE & 10 & 0 & 0.00 & & & \\
\hline SOS & 200 & 20 & 10.00 & & & \\
\hline HIS & 10 & 0 & 0.00 & & & \\
\hline MTH & 10 & 0 & 0.00 & & & \\
\hline CRS & 10 & 0 & 0.00 & & & \\
\hline ENG & 50 & 0 & 0.00 & & & \\
\hline
\end{tabular}

ISC $=$ Integrated Science, $\mathrm{PES}=$ Primary Education Study, BED=Business Education, $\mathrm{CSC}=\mathrm{Computer}$ study, $\mathrm{PHE}=\mathrm{Physical}$ and Health Education, $\mathrm{SOS}=\mathrm{Social}$ Study, HIS= History, AED=Agric. Education, $\mathrm{MTH}=$ Mathematics, $\mathrm{CRS}=$ Christian Religious Study, ENG=English

\section{Discussion}

The prevalence of $P$. falciparum was $15.49 \%$. This is an indication that malaria infection is quite high among the new intakes. It also highlights that the new intake may serve as repository for further transmission of malaria parasite in the school. The present result was comparable with the $17.4 \%$ prevalence reported among students in University of Maiduguru, Nouthern Nigeria [13]. However, the present result was lower than $61.1 \%$ prevalence rates reported from undergraduate students in Abuja, Nouthern Nigeria [18], $35.3 \%$ at the Abia State Polytechnics, Southeastern Nigeria [12], 45.79\% prevalence from the Federal University of Technology, Akure, South western Nigeria [14]. Abah and Temple [19] reported a prevalence of $63.3 \%$, which was fourfold higher than the present result among primary school pupils in the same ecological zone. These disparities might be due to differences in the environmental and climatic conditions in various parts of the country. The study was carried out at different month. The present study was undertaken between January and March, which correspond with the time were malaria transmission is minimal. The prevalence in this present study is an indication that malaria is all season in the study locations. However, the sharp disparity between this present study and that of Abah and Temple [19] may be attributed to the age differences of the population. The populations in [19] range between5-9 years. High prevalence at the age bracket has been reported [13].

The high prevalence of Plasmodium falciparum among the male students than the female agrees with Afolabi [14]. He reported $(55.9 \%)$ prevalence in male and $(35.2 \%)$ in the female students. In this present study, high prevalence in male than in female was no significant. This is an indication that both the male and female in schools had equal chances of contracting malaria infection. This is because both students have similar exposure to biteof female Anopheles mosquitoes as they prefer to read in unprotected classrooms.

High prevalence among age bracket 29- 30 years in this 
present study has been observed by earlier report [20]. However, the result contrasted the report of Afolabi et al. [14], who observed that higher prevalence was among the age bracket 16-20 years. Variation in the age prevalence among the students was not significant. This indicates that all students, irrespective of their age had equal chances of been infected as long as they are confined to the same environmental conditions.

\section{Conclusion}

Malaria prevalence among the students was moderately high. This prevalence could impact negatively on the health of student population. Improving hygienic conditions and periodic insecticides spray in both hostels and their reading halls can go a long way in reducing the mosquito population and thus reduce transmission. It is recommended therefore, that government should include tertiary institutions in malaria control programmes. School authorities should also assist government in providing malaria treatment and preventive prophylaxis for both new intake and old students. A functional Sick Bay with a qualify doctor should also be put in place.

\section{References}

[1] World Health Organization (WHO) (2012). Map of malaria endemic countries.

[2] World Health Organization (WHO) (2016) "Malaria Fact Sheet”. http://www.Who.int/mediacentre/factsheets/

[3] Murphy O, John JA, Sergi S, Hassan M, Pedro A, Clara M. (2001). Risk factors for Presentation to Hospitals with Severe Anaemia in Tanzanian Children: a Case-Control Study. Tropical Medicine and International Health; 7(10):823-30.

[4] World Health Organisation (WHO) (1990): World Report of the tropical disease, World Health Organisation feature, No. 139 , Geneva.

[5] World Health Organisation (WHO) (1997): Health and Environment in sustainable development five years of the Earth summit Geneva, 19133.

[6] Florence. O A, Pat. U O, Elizabeth N O and Mercy OI (2014). Malaria infection amongst students of the university of Benin, Edo State, Nigeria. International journal of recent scientific research vol. 5(9) 1529-1532.

[7] Holding PA, Stevenson J, Peshu N, Marsh K. (2001). Cognitive sequence of severe malaria with impaired consciousness. Oxford Journals Medicine and Health Transactions; 93(5):529-34.
[8] World Health Organization 2006; Geneva, Switzerland, Pp 1518.

[9] Okwa O O., L. Sanyaolu and A. F. Olatokunbo (2012) "Malaria and working performance of academic staff in Nigerian University," Research Journal of Biology. Vol 2(5), 151-156.

[10] Udonwa, N. E. GyuseA. N. and EtokidemA. J. (2010) "Malaria: knowledge and prevention practice among school adolescents in a coastal community in Calabar, Nigeria," African Journal of Primary Health Care and Family Medicine. Vol 2(1).

[11] Leighton C, Foster R. (1993). Economic impact of malaria in Kenya and Nigeria. Applied Reasearch paper No 6. Abt Associates in collaboration with vector biology control project medical service cooperation International.

[12] Ezeigbo, O R. and Ezeigbo, I C. (2016). Malaria and Soil Transmitted Helminthes co-infection among Abia State Polytechnic Students, Aba, Southeastern Nigeria. International Invention Journal of Medicine and Medical Sciences Vol. 3(5) pp. 68-71.

[13] Adesina O. O (2013). Subclinical Malaria Infection Among University of Maiduguri students: Prevalence And Parasite Density BOMJ Vol. 10, NO. 1, 6-11.

[14] Afolabi, O. J, Simon-Oke, I. A, Sorungbe, A. A, Alao, O. O. (2015). Prevalence of Malaria among Biological Science Students in Federal University of Technology Akure, Nigeria Nature and Science; 13(2) http://www.sciencepub.net/nature.

[15] Okwa OO, Babatunde B. and OlundegunS. (2011). "Social aspectof Malaria among two tertiary institutions in Lagos State, Sierra loene Journal of Biomedical Research. Vol (3) 2, 97-103. August, 2011.

[16] World Health Organisation (WHO) (1998): Examining blood film for malaria parasites. Bench aids for the Diagnosis of Malaria $1-8$ plates, World Health Organization.

[17] Public Health Ontario (PHO) (2013). Best Practices for cleaning Disinfection and Sterilization of Medical Equipment/Devices in all Health Care Setting $3^{\text {rd }}$ edition. Retrieve on July 162015.

[18] 18. Mature BM, Azare BA, Ugbong L. (2001). The Prevalence of Malaria parasites amongst Undergraduate Students of University of Abuja. The Nigerian Journal of Parasitology; 22(182): 49-82.

[19] Abah AE and Temple B (2015). Prevalence of Malaria Parasite among Asymptomatic Primary School Children in Angiama Community, Bayelsa State, Nigeria, Trop Med Surg 4:1, http://dx.doi.org/10.4172/2329-9088.1000203

[20] 20. Falade CO, Olayemi O, Dada-AdegbolaHO, Aimakhu CO, Ademowo OG, SalakoLA. (2012). Prevalence of malaria at booking among antenatal clients in a secondary health care facility in Ibadan, Nigeria. Afr J Reprod Health. 12:141-52. 